\title{
PROFESSOR, TUTOR OU COACH? REFLEXÕES SOBRE A DOCÊNCIA EM UM CONTEXTO DE CAPITALISMO FLEXÍVEL E EMOCIONAL
}

\author{
TEACHER, TUTOR OR COACH? REFLECTIONS ON TEACHING IN A FLEXIBLE AND EMOTIONAL \\ CAPITALISM CONTEXT
}

\section{¿MAESTRO, TUTOR O COACH? REFLEXIONES SOBRE LA ENSEÑANZA EN UN CONTEXTO DE CAPITALISMO FLEXIBLE Y EMOCIONAL}

\author{
Renata Porcher Scherer ${ }^{1}$ \\ Patrícia Gräff ${ }^{2}$
}

\begin{abstract}
Resumo: O presente artigo investiga os efeitos de uma educação centrada nos interesses e necessidades dos estudantes sobre a docência. O posicionamento do professor como tutor ou coach, nesses modelos pedagógicos, provoca o esmaecimento do ensino como principal função docente. Para o exercício analítico sobre um conjunto de publicações nacionais, que defendem a utilização do método coaching no trabalho docente, pautou-se nos Estudos Foucaultianos, usando o conceito de prática como ferramenta metodológica. Entende que a constituição de um capitalismo flexível e emocional produz as condições para a emergência do método coaching na educação. Conclui que os modelos pedagógicos baseados no método coaching, ao posicionarem os docentes como motivadores dos interesses dos alunos e ao responsabilizarem os estudantes pela escolha de seus processos formativos, bem como pelos resultados desses processos, tendem a fragilizar os sentidos públicos e democráticos concernentes à docência, na Contemporaneidade.
\end{abstract}

Palavras-chave: Docência. Práticas pedagógicas. Cultura coaching.

\begin{abstract}
This article investigates the effects on teaching of an education centered on the interests and needs of students. The position of the teacher, in these pedagogical models, as tutor or coach of the students, causes the fading of teaching as the main teaching function. The analytical exercise on a set of national publications, which defend the use of the Coaching method in teaching work, was based on Foucauldian Studies, using the concept of practice as a methodological tool. It is understood that the constitution of a flexible and emotional capitalism produces the conditions for the emergence of the Coaching method in education. It is concluded that the pedagogical models based on the Coaching method, by positioning the teachers as motivators of the students' interests
\end{abstract}

\footnotetext{
${ }^{1}$ Instituto Federal de Educação Ciência e Tecnologia Sul-rio-grandense. Camaquã, Rio Grande do Sul, Brasil.

${ }^{2}$ Universidade Federal da Fronteira Sul. Chapecó, Santa Catarina, Brasil.
} 
and making the students responsible for the choice of their training processes and the results of these processes, tend to weaken the public and democratic meanings concerning teaching, in Contemporaneity.

Keywords: Teaching. Pedagogical practices. Coaching Culture.

Resumen: El presente artículo tiene como foco investigar los efectos que la producción de una educación centrada en los intereses y necesidades de los estudiantes, puede producir sobre la docencia, comprendiendo que el posicionamiento del profesor, en esos modelos pedagógicos, como tutor o coach de los alumnos, provoca el desvanecimiento de la enseñanza como principal función docente. Para el ejercicio analítico sobre un conjunto de publicaciones nacionales, que defienden la utilización del método Coaching en el trabajo docente, se basó en los Estudios Foucaultianos, usando el concepto de práctica como herramienta metodológica. Entiende que la constitución de un capitalismo flexible y emocional produce condiciones para la emergencia del método Coaching en la educación. Concluye que los modelos pedagógicos basados en el método Coaching, al posicionar a los docentes como motivadores de los intereses de los alumnos y responsabilizar a los estudiantes por la elección de sus procesos formativos y por los resultados de esos procesos, tienden a debilitar los sentidos públicos y democráticos concernientes a la docencia, en la Contemporaneidad.

Palabras clave: Docencia. Prácticas pedagógicas. Cultura Coaching.

\section{INTRODUÇÃO}

No ano de 2015 foi anunciada, em um jornal do interior do Rio Grande do Sul, a inauguração de uma escola referência para o Ensino Médio. A inovação do modelo pedagógico proposto pela escola consistia em duas questões, a saber: avaliação e acompanhamento. Enquanto a avalição ocorreria com base em uma contínua retomada dos estudos e na proposição de novos desafios, o acompanhamento, ligado às questões da descoberta vocacional, aconteceria pela mediação de um professor que, neste modelo pedagógico, foi denominado como coach. (JONAL VS, 2015). No ano seguinte, a Revista Pátio abordou a temática da educação customizada. Em sua 78a edição, a revista organizou uma entrevista com a encarregada pelas relações de mercado do modelo de escolas Summit, Mira Browne. Na entrevista, Browne afirma que: “os professores são o coração do modelo educativo das Escolas Públicas Summit" (PÁTIO, 2016, s/p), visto que a aprendizagem dos escolares é desencadeada por meio de processos de tutoria, oferecida pelos docentes.

Os registros escolhidos para abrir esse artigo apresentam, em comum, duas questões que acreditamos merecer nossa atenção. A primeira, relacionada à necessidade de pautas formativas cada vez mais individualizadas, constituindo uma educação customizada; a segunda, ligada ao posicionamento dos professores como tutores ou coaches dos estudantes. Neste estudo, interessa- 
nos interrogar sobre a proliferação desses modelos pedagógicos e sobre os efeitos que a individualização dos percursos educativos produz sobre a docência. Para isso, realizamos um mapeamento de pesquisas - em periódicos nacionais - que têm se dedicado à temática Coaching no campo educacional. Selecionamos três pesquisas, que ganharam destaque pelas contribuições que trazem para pensar a proliferação de uma ênfase Coaching na educação, para analisarmos de forma mais detalhada. Através da leitura e do estudo dessas pesquisas, destacamos um conjunto de práticas que constituíram a superfície analítica deste trabalho.

Nossas análises tomam o conceito de prática como ferramenta metodológica, inscrevendo a pesquisa no campo dos Estudos Foucaultianos. Importa registrar que, por prática, circunscrevemos uma certa racionalidade, uma regularidade que orienta as ações e os discursos dos indivíduos (CASTRO, 2009). Assim, as práticas teriam relação tanto com aquilo que pode "ser descrito, analisado e problematizado quanto, ao mesmo tempo, [com] o domínio das próprias descrições, análises e problematizações que são colocadas em movimento" (VEIGA- NETO, 2008, p. 7). Para Foucault, tudo seria prática e tudo estaria imerso em relações de saber que se implicam mutuamente (FISCHER, 2012). "Enunciados e visibilidades, textos e instituições, falar e ver constituem práticas sociais por definição permanentemente presas, amarradas às relações de poder, que as supõem e as atualizam" (FISCHER, 2012, p. 75).

Dadas as coordenadas que orientam, metodologicamente, o nosso olhar sobre os materiais, importa marcar a temporalidade das pesquisas analisadas, que se concentra entre os anos de 2016 e 2017, apontando para um modo bastante recente de direcionar os percursos educacionais. Embora estudos sobre um tipo de instrução personalizada circulem, em distintas áreas, desde os primeiros anos do século XXI e experiências com essa ênfase, na educação escolarizada, apareçam na forma de projetos pontuais desde, pelo menos, o ano de 2010, o registro e a publicação científica de uma ênfase coaching na educação escolarizada desponta, predominantemente, a partir do ano de 2016.

Partindo dessas pontuações iniciais, sinalizamos que o foco deste artigo se concentra nos efeitos de uma educação centrada nos interesses e necessidades dos estudantes - uma educação customizada - sobre a docência. Nesses modelos pedagógicos, o professor se posiciona como tutor ou coach dos alunos. Ao fazê-lo, a principal função docente - o ensino - fica esmaecida, em detrimento de ações como acompanhar, facilitar ou conduzir a aprendizagem dos alunos. Biesta (2016), em artigo publicado recentemente, afirma que podemos estar presenciando o desaparecimento do ensino e dos professores. Com essa afirmativa, o pesquisador ressalta que não 
está diagnosticando o fim da profissão professor, mas que deseja alertar para "a erosão - de uma certa maneira de compreender o ensino e o professor, compreensão dentro da qual está o reconhecimento de que os professores estão aqui para ensinar" (BIESTA, 2016, p. 120).

Para organizar a escrita e esboçar os elementos que fundamentam a constituição do argumento central, dividimos o texto em três partes. Na primeira, apresentaremos um breve diagnóstico sobre as principais modificações com relação à docência, a partir de novos modelos de capitalismo. Na segunda parte, tensionaremos os pontos que nos parecem produzir as condições de emergência para a composição de uma cultura coaching na educação contemporânea, a partir da produção de um capitalismo flexível e emocional. Nesta seção, apresentaremos os artigos analisados e descreveremos as práticas relacionadas a uma nova forma de ser docente pautada pela cultura coaching. Na terceira parte, por fim, encaminharemos as amarrações para concluir o texto, fazendo uma defesa da docência e do ensino.

\section{ANOTAÇÕES SOBRE A DOCÊNCIA}

Diferentes estudos têm apontado para uma transformação significativa nos modos como a docência vem sendo pensada contemporaneamente (HARGREAVES, 1998; NÓVOA, 2009; TARDIF \& LESSARD, 2014). O pesquisador português António Nóvoa, ao realizar um diagnóstico sobre as transformações ocorridas na educação escolarizada ao longo do último século, sinaliza que a instituição escolar tem ocupado, de forma cada vez mais central, o compromisso com a formação para a cidadania, aumentando significativamente o seu campo de atuação. Nas palavras do pesquisador, esse movimento tem gerado uma "acumulação de missões e de conteúdos, numa espécie de transbordamento, que a levou a assumir uma infinidade de tarefas" (NÓVOA, 2009, p. 52). Essa produção de uma escola transbordante seria fruto de uma ambição pedagógica que, segundo Silva (2015a, p. 9), "conduziu as práticas escolares a um alargamento desmedido que implicava na formação dos sujeitos escolares em todas as dimensões possíveis". A problemática apontada por Nóvoa (2009), relacionada a essa multiplicação de funções das instituições escolares, parece-nos fruto de um esmaecimento de foco na constituição de suas funções. Dito de outra maneira, a escola parece ter perdido a noção de suas prioridades. A proliferação de campos de conhecimento que reivindicam espaço no currículo e nas práticas escolares provoca uma descentralização das funções da escola, ampliando-as para além da promoção das aprendizagens. Nesse registro, um dos grandes perigos dos tempos atuais, segundo Nóvoa $(2009$, p. 67), seria a 
produção de uma escola de duas velocidades, "uma escola concebida essencialmente como um centro de acolhimento social, para os pobres [... e]; por outro lado, uma escola claramente centrada na aprendizagem, e nas tecnologias, destinada a formar os filhos dos ricos".

A partir da problematização de Nóvoa (2009) sobre a "escola transbordante", parece-nos possível pontuar que o transbordamento das funções assumidas pela escola ocasiona, como um dos efeitos possíveis, o transbordamento da docência, que passa a assumir uma infinidade de tarefas que, como aponta o pesquisador, não tem necessariamente uma relação com o conhecimento e com a promoção das aprendizagens - tarefas que compõem o núcleo da atividade escolar. Dentro desse contexto, podemos afirmar que "as responsabilidades dos professores são cada vez maiores e os seus papéis mais difusos" (HARGREAVES, 1998, p. 131), permitindo que uma nova compreensão da docência seja constituída, a partir de um cenário que preconiza a oferta de uma educação, cada vez mais, customizada.

Como nos mostram Tardif e Lessard (2014, p. 25), para compreendermos as transformações do trabalho docente, precisamos interrogar os modelos de gestão e de realização desse trabalho. Segundo eles, "pode-se dizer que a escola e o ensino têm sido historicamente invadidos e continuam ainda a sê-lo, por modelos de gestão e de execução do trabalho oriundos diretamente do contexto industrial e de outras organizações econômicas hegemônicas". Para os autores, a configuração do campo educacional, a partir dos modelos advindos do trabalho tecnológico, instrumentalizaria a caracterização do ensino como "tratamento de informação". O mesmo aconteceria com as novas abordagens do trabalho, fazendo com que expressões como flexibilidade, competência, responsabilidade, eficácia e necessidade de resultados passem a compor a pauta pedagógica contemporânea. O problema dessa tradução, dos modelos de gestão e execução do trabalho para a docência, consistiria no fato de que tais procedimentos e expressões são utilizados "sem se dar ao trabalho de questionar sua validade e sobretudo de avaliar seu impacto sobre os conhecimentos escolares, o ensino e a aprendizagem dos alunos" (TARDIF; LESSARD, 2014, p. 25).

Pensin (2017, p. 164), em sua Tese de Doutorado, analisa a constituição da docência na Educação Superior e aponta para os modos como "os elementos relacionados à produtividade, à competitividade, à concorrência, ao empreendedorismo, à inovação técnica, ao pragmatismo e ao ajuste entre o conjunto de ofertas e de demandas de emprego" vêm conformando a docência nessa etapa da escolarização. Embora o foco deste artigo não recaia sobre o Ensino Superior especificamente, entendemos que esses elementos, em alguma medida, perpassam a composição da Educação Básica, sobretudo com a ênfase na singularidade de processos formativos, que visa, ao 
fim e ao cabo, potencializar a concorrência, produzindo no indivíduo as condições de participação em um mercado bastante competitivo.

Para Masschelein e Simons (2014a, p. 131), o professor "ocupa um papel particularmente especial" na constituição da escola como espaço para o exercício do tempo livre, dado pelo compartilhamento do mundo, entre crianças e jovens. Ao descreverem o professor como uma "figura pedagógica" e não como um tipo histórico, sociológico ou psicológico, os pensadores nos convidam a revitalizar a utilização da expressão "mestre - escola", marcando uma posição para a docência, que reafirma o lugar do professor como uma "figura pedagógica e um mestre, ao mesmo tempo dedicado e bem versado em seu assunto" (MASSCHELEIN; SIMONS, 2014a, p. 131).

No registro dos estudos até aqui brevemente revisados, podemos inferir que uma "cultura do empreendedorismo" (GADELHA, 2013), que busca fazer dos indivíduos microempresas levando-os a assumir, em sua constituição, traços como: proatividade, inovação, senso de oportunidade e capacidade de provocar e se adaptar a mudanças -, tem produzido novas configurações para pensar a docência em tempos de uma educação customizada. Qualidade, profissionalismo e flexibilidade parecem substituir perseverança, conviç̧ão e confiança, como apontam Masschelein e Simons (2014a). Nesse cenário, a técnica da flexibilização produz um professor "que nunca está empregado, mas pode ser posicionado em qualquer lugar" (MASSCHELEIN; SIMONS, 2014a, p. 146, grifos dos autores). Desejamos mostrar, neste artigo, como os materiais analisados, ao posicionarem o professor como facilitador das aprendizagens, tutor ou coach do percurso formativo dos alunos, têm produzido novos sentidos para docência.

\section{CAPITALISMO FLEXÍVEL E EMOCIONAL: CONDIÇÕES PARA A EMERGÊNCIA DE UMA CULTURA COACHING}

Uma cultura coaching vem sendo produzida em diversos campos do saber, na Contemporaneidade. Para esta pesquisa interessa compreender como esse modo de conduzir as práticas na docência tem orientado o campo educacional. Para isso, analisamos um conjunto de técnicas descritas nos artigos que compõem a materialidade analítica desta pesquisa, a fim de entender como operam e produzem uma atmosfera que orienta as práticas pedagógicas. É essa atmosfera que conforma aquilo que viemos denominando como cultura coaching, cuja emergência nos parece possível a partir da composição de um capitalismo flexível e emocional. Nessa esteira, a cultura coaching constitui um conjunto de referentes que, quando incorporados ao contexto 
educacional, passam a orientar as práticas empreendidas na escola e, por consequência, as possibilidades de aprendizagem e as relações produzidas entre professores e alunos. As condições de possibilidade para a emergência dessa ênfase coaching na educação e os efeitos que tem produzido sobre esse campo constituem o foco desta seção.

Destacamos que duas das questões que nos parecem nucleares para compreender a docência em tempos de educação customizada e de uma cultura coaching são: a centralidade na flexibilidade e na emotização. Nesse contexto, caberia ao coach (profissional que coordena o processo ou professor) identificar as singularidades dentro de um coletivo e desenvolver uma proposta pedagógica pautada pelas diferenças, e; ao coachee (cliente ou aluno) projetar mudanças e construir estratégias, a partir de um ponto de ação. Essa necessidade de inovação permanente e de um trabalho cada vez mais individualizado, orientado por singularidades, parece encontrar um solo fértil para se fortalecer no contexto de um capitalismo flexível (SENNETT, 1999). Já as técnicas utilizadas no trabalho de coaching, que utilizam como ferramentas principais o trabalho de reprogramação mental e emotização - que descreveremos a seguir -, parecem ter como base o fortalecimento de um capitalismo emocional (ILLOUZ, 2007; HAN, 2016).

Para o sociólogo Richard Sennett (1999), na Contemporaneidade, o capitalismo se caracteriza, preponderantemente, a partir da flexibilidade. De acordo com ele, a centralidade na flexibilidade pode estar sustentada em três aspectos: (1) a reinvenção contínua das instituições, que se refere a novas formas organizativas, que aumentem a eficiência e a produtividade; (2) a especialização flexível, que implica na constituição da inovação permanente, pautada por estratégias de comunicação, cada vez mais velozes, e pela competitividade; (3) a concentração sem centralização - uma nova forma de organização do trabalho, regulada por novas formas de controle, vinculada à criação de metas (normalmente de difícil cumprimento) e a busca pela qualificação das performances. Segundo Silva (2015b), quando analisamos a produção subjetiva que perfaz o mundo do trabalho no capitalismo flexível, na obra de Richard Sennett (1999), percebemos que um dos pontos mais importantes é a sua reflexão sobre a disposição ao risco. Nas palavras do autor (2015b, p. 26), "o sujeito fabricado nesse jogo de relações busca permanentemente as inovações, não se apega a estruturas burocráticas ou a experiências duráveis. Vive a imediaticidade, visando novas oportunidades e mudanças que podem ocorrer em qualquer tempo". Aqui, as experiências profissionais são pouco valorizadas em detrimento da disposição à mudança. Além da disposição ao risco, outro ponto importante nas análises de Sennett $(1999$, p. 118) refere-se à necessidade do trabalho em equipe, que teria relação com uma nova ética no trabalho: 
O trabalho em equipe é a ética de trabalho que serve a uma economia política flexível. Apesar de todo o arquejar psicológico da administração moderna sobre o trabalho de equipe no escritório e na fábrica, é o etos de trabalho que permanece na superfície da experiência. O trabalho de equipe é a prática de grupo da superficialidade degradante.

Outro ponto analisado por Silva (2015b), ainda relacionado à emergência da necessidade do trabalho em equipe, teria relação com a intensificação de controle subjetivo e com a mobilização de um poder sem autoridade. Assim, trabalhar em equipe exigiria capacidade de distanciamento, resolução de problemas e proatividade. Sob as condições do capitalismo flexível, descrito por Sennett (1999), as disposições para arriscar-se e reinventar-se emergem como virtudes fundamentais. Porém, essa nova configuração acaba por expor "os indivíduos a vulnerabilidades permanentes, através das quais lançam-se a processos continuados de capacitação" (SILVA, 2015b, p. 29).

Pela caracterização de um tipo de capitalismo flexível, Sennett (1999) descreve elementos comuns à produção de uma cultura coaching na educação. Ser flexível, estar em constante processo de capacitação e aprimoramento e ser proativo são caraterísticas fundamentais para que os indivíduos tenham alta performance, na grade de leitura coaching. Nessa chave, o autoconhecimento e a reinvenção constante de si e de suas formas de aprender, a partir das orientações contidas no plano traçado pelo professor/coaching, constituiriam garantias de sucesso para a aprendizagem.

Se a necessidade de se reinventar continuamente é uma das exigências tanto para professores como para alunos, em um contexto de capitalismo flexível, a organização de um trabalho pedagógico pautado pelas emoções e sentimentos traduz elementos importantes dentro de uma racionalidade capitalista, que tem se modificado para produzir valor a partir de uma centralidade nas emoções. Illouz (2007), ao analisar a dimensão emocional no capitalismo, aponta que tal dimensão seria gerida pelo axioma do controle e da gestão emocional. Tal axioma teria sido produzido e manter-se-ia fortalecido pelos discursos da autoajuda. Assim, o capitalismo emocional constitui uma cultura em que as práticas emocionais e econômicas teriam uma relação de imanência e produziriam um deslocamento a partir do qual "o afeto se transforma em um aspecto essencial do comportamento econômico e na vida emocional" (ILLOUZ, 2007, p. 19-20).

Han (2016) indica outros pontos que podem ser analisados, a partir do trabalho desenvolvido por Illouz (2007), e nos apresenta um diagnóstico importante para compreendermos as nuances que o capitalismo das emoções adquire em um contexto neoliberal. Para Han (2016, p. 38), o 
"regime neoliberal pressupõe as emoções como recursos para incrementar a produtividade e o rendimento". Nessa esteira, hoje se exigiria dos trabalhadores não apenas competência cognitiva, mas também competência emocional. As emoções transformam-se em matéria-prima, dentro de um contexto de capitalismo das emoções. O pensador assinala que essas transformações indicam uma mudança de paradigma, especialmente na forma de pensarmos o novo perfil de trabalhador que a Contemporaneidade exige. Estaríamos passando de um management racional para um management emocional. A motivação, como mostra o autor, tem uma ligação estreita com as emoções, pois "as emoções positivas são o fermento para o crescimento da motivação" (HAN, 2016, p. 40). Importa, nesse momento, interrogar pelos sentidos que são atribuídos à docência em um contexto de capitalismo flexível e emocional, a partir do estabelecimento de uma cultura coaching. Para tanto, optamos por explorar um conjunto de práticas descritas em artigos publicados em periódicos nacionais, que defendem a utilização do método coaching para o trabalho em educação.

Ao iniciarmos a descrição da materialidade estudada, chamamos a atenção para os títulos das pesquisas selecionadas, pois nos parecem ilustrar os contornos que a ênfase coaching, como método educacional, vem ganhando na Contemporaneidade. Um único título está organizado a partir de uma interrogação: Coaching na Educação?, trazendo um tom de dúvida que se dissipa ao longo do texto, mas que ilustra uma desconfiança sobre o seu uso como método válido para a educação escolarizada. Os demais estudos assumem e defendem o coaching, desde os títulos Coaching na educação e Coaching na aula de Sociologia - como um método relevante para a educação deste tempo, adequado às necessidades de uma sociedade individualizada e performática.

O uso do termo performance, em um dos títulos - Coaching na Educação: uma metodologia de alta performance -, explicita um conceito central tanto para os contornos que vêm sendo desenhados pela sociedade, na Contemporaneidade, como para a ênfase coaching: a performatividade. Para Dardot e Laval (2016), existe uma estreita relação entre a proliferação do método coaching e a fabricação do sujeito neoliberal, ou como os autores denominam, o "neossujeito", dado pela centralidade no conceito de performance. Sobre esse entendimento, "o novo sujeito é o homem da competição e do desempenho" (DARDOT; LAVAL, 2016, p. 353), visto que o coaching teria sido o modelo que auxiliou na naturalização e no fortalecimento da competitividade. Nas palavras dos autores, "foi esse modelo, talvez mais do que o discurso econômico sobre a competitividade, que permitiu 'naturalizar' esse dever de bom desempenho e difundiu nas massas certa normatividade centrada na concorrência generalizada" (DARDOT; LAVAL, 
2016, p. 354). O "neossujeito" seria produzido pelo dispositivo "desempenho/gozo", diferente do sujeito do capitalismo industrial, cujos sacrifícios no trabalho eram compensados pelo consumo e pela espera de um gozo futuro, advindo de bens acumulados. A vida do sujeito neoliberal torna-se, em todos os seus aspectos, objeto do dispositivo "desempenho/gozo". Assim, o bom desempenho torna-se um dever e o gozo um imperativo.

Ressaltar apenas a tensão entre ambos seria esquecer tudo o que estabelece certa equivalência entre o dever do bom desempenho e o dever do gozo, seria subestimar o imperativo do 'sempre mais' que visa intensificar a eficácia de cada sujeito em todos os domínios: escolar e profissional mas também relacional, sexual etc. (DARDOT; LAVAL, 2016, p. 356).

Conexões entre o conceito de performatividade e a prática pedagógica constituem o eixo central do método coaching. Nessa grade de leitura, destacamos o estudo realizado por Hattge (2014, p. 15) que, em sua Tese de Doutorado, analisa o movimento Todos pela Educação, no Brasil, e defende que a performatividade se "articula aos conceitos de inclusão e aprendizagem. Para operar, ela necessita de um processo de reconfiguração da aprendizagem em desempenho". Embora a autora não tenha se dedicado ao estudo do método coaching, parece-nos possível fazer aproximações entre o conceito de performatividade, usado por ela para problematizar as práticas de inclusão educacional, e o conceito de performatividade, como objetivo central do método coaching, que passa a compor a pauta educacional, nas práticas pedagógicas organizadas sob a sua ênfase. Em ambos os contextos, a performatividade é dada pelo desempenho do indivíduo, a partir da organização de um acompanhamento educacional personalizado e executado individualmente

O processo de coaching busca constituir-se como uma alternativa para o desenvolvimento do coachee, não somente em seus aspectos cognitivos, mas incluindo, também, os aspectos emocionais, olhando para "o homem como ser complexo, dinâmico e singular" (MATTEU CORREIO; MATTEU CORREIO, 2016, p. 47). Nesse registro, os autores apresentam duas práticas para o trabalho pelo método coaching na Educação: o ensaio cognitivo e a emotização. O ensaio cognitivo busca fomentar que o coachee utilize a imaginação, de forma repetitiva, para criar uma referência relacionada ao seu objetivo no campo mental, tomando como base a premissa de que "o que acontece no mundo exterior deve ocorrer primeiramente no mundo interior" (MATTEU CORREIO; MATTEU CORREIO, 2016, p. 50). Assim, caberia ao professor-coach estimular os alunos a ensaiarem mentalmente uma nova habilidade ou o alcance de um objetivo. Os autores, ao defenderem uma proposta de trabalho pedagógico que atue no campo mental dos alunos, apontam que seria possível estimular a mente humana conduzindo para estados diversos. Deste modo, 
[...] alguns professores tornam as aulas bem humoradas, divertidas, podendo deixar os alunos relaxados e curiosos para aprender, ou também é possível deixá-los tensos, oprimidos, inseguros, traumatizados, amedrontados entre outros estados, essa indução de estados estão intimamente ligados a alta performance do professor na condução da turma, sua postura, fala e perguntas estimulam esse estado (MATTEU CORREIO; MATTEU CORREIO, 2016, p. 51).

Destacamos o modo como, em um contexto de capitalismo cognitivo e emocional, a docência parece se ressignificar, assumindo novas funções, como a indução de estados mentais, para, então, atingir uma alta performance de condução da turma. Para atender a esses pressupostos, o professor-coach precisa constituir-se um motivador da turma, através de sua postura, de sua fala e de perguntas que direcionem a aprendizagem. "O Coaching age no despertar da consciência, e pode transformar uma pessoa, ao aflorar o senso de autor responsabilidade, uma vez assumindo o papel de condutor que dirige sua própria vida" (MATTEU CORREIO; MATTEU CORREIO, 2016, p. 52).

O posicionamento do professor como motivador do interesse da turma ou de cada aluno em particular precisa ser colocado sob suspeita. Para Masschelein e Simons (2014a), mais do que uma questão de motivação, os processos educativos deveriam ser uma questão de criar interesse, de trazer à vida, de formar o aluno. Assim, o processo formativo não deveria ser uma atividade auxiliar da escola e dos espaços educativos; em vez disso, a formação teria relação "com a orientação dos alunos para o mundo como ele é construído para existir no sujeito ou na matéria, e essa orientação diz respeito, principalmente, à atenção e ao interesse para com o mundo e, igualmente, à atenção e ao interesse para com a própria pessoa em relação ao mundo" (MASSCHELEIN; SIMONS, 2014a, p. 45). Na medida em que os alunos estivessem preocupados com a abertura do mundo, a atenção seria de importância crucial para que se estabelecesse a relação educativa e não a motivação. Seria este o momento mágico em que, segundo os autores, "alguma coisa fora de nós mesmos nos faz pensar, nos convida a pensar ou nos fazendo coçar a cabeça" (MASSCHELEIN; SIMONS, 2014a, p. 45). Nesse instante, a matéria deixaria de ser uma ferramenta ou um recurso para se tornar algo real, que nos faz estudar e praticar.

Outro estudo, intitulado Coaching na Educação? Pesquisa-ação com gestores escolares, investigou a experiência de coaching no contexto educacional, com foco no trabalho com gestores escolares. Para as autoras, tal proposta, mesmo sofrendo uma resistência inicial dos participantes, por aplicar uma metodologia do campo empresarial no campo escolar, teria permitido aos gestores reverem suas práticas profissionais e projetarem mudanças necessárias no campo em que atuam 
(BIRCK; ZILIOTTO, 2017). As autoras apontam que "coaching é um processo estruturado que auxilia pessoas a atingirem suas metas em sua vida pessoal, suas carreiras, seus empreendimentos ou organizações" (BIRCK; ZILIOTTO, 2017, p. 168). Portanto, seria possível, através desse processo, aperfeiçoar e aprofundar a aprendizagem, melhorar as performances e aumentar a qualidade de vida. Importa marcar que o trabalho realizado com gestores escolares parece se inserir no registro, já descrito nessa seção, do capitalismo flexível e do capitalismo emocional. O programa oferecido, ao incentivar o trabalho através de metas e projeção de mudanças, conduz cada participante à necessidade de, ao mesmo tempo em que se mantém em constante processo de capacitação, assumir a gestão de sua vida pessoal e carreira como um empreendimento.

O terceiro e último conjunto de práticas coaching, que analisamos neste artigo, consiste em um trabalho pedagógico realizado nas aulas de sociologia, com uma turma de Ensino Médio. As estratégias privilegiadas pelo professor-coach, nesse estudo, foram: a roda de conhecimento, constituída pelo mapeamento dos conhecimentos prévios dos alunos sobre os conteúdos que iriam ser estudados naquele ano; a tríade do tempo, produzida pelo registro de quanto tempo se investe em fatos que são categorizados como importantes, urgentes ou circunstanciais; a escala, que avalia o nível de acompanhamento e comprometimento dos alunos no processo, e; o patrocínio positivo, caracterizado por palavras de estímulo e elogio, objetivando à elevação da autoestima e o destaque das reações consideradas como corretas. Nas palavras do autor, "uma palavra de incentivo sincero deve sempre brotar de toda e qualquer situação" (SILVA, 2016, p. 196). Como podemos perceber, as práticas descritas nesse terceiro estudo tomam por base o método coaching, sendo utilizadas como ferramentas pedagógicas e dando centralidade para a motivação do aluno através da autoavaliação. Esses elementos ficam visíveis, sobretudo, pela técnica da escala e pelo incentivo, colocado em operação pelo patrocínio positivo. O objetivo desse processo, segundo o autor, seria "desenvolver no aluno o poder de escolha do seu destino, desmistificando a sociedade e tirando dela seu poder de produtora de realidade e tornando-a uma consequência dos atos dos indivíduos, tornando-os protagonistas da própria história" (SILVA, 2016, p. 201).

Como já sinalizamos anteriormente, o posicionamento do professor como motivador/ incentivador dos alunos nos parece problemático, pois indica a subversão do papel público e democrático das escolas. De acordo com Masschelein e Simons (2014b, p. 174), existiriam duas formas de pensarmos o papel público das escolas. Para os autores, a primeira confere à escola um significado público ao entendê-la como o espaço "que possibilita que as pessoas vivam no mundo, referido como a esfera pública". A escola, nessa linha de pensamento, seria "concebida como uma 
introdução ao mundo como espaço público". Uma segunda forma de compreensão da escola como espaço público ultrapassa a introdução dos indivíduos ao mundo e se produz a partir de uma inspiração no pensamento arendtiano, o que implica assumir uma responsabilidade como educadores "para preservar tanto o mundo (por meio da renovação) quanto o novo começo, os professores (nas escolas) têm que ser conservadores, isto é, para aceitar (amar) o mundo" (MASSCHELEIN; SIMONS, 2014b, p. 175). Ser conservador, nessa perspectiva, consiste em refrear um desejo de preparar os jovens para um novo mundo, pois isso significaria tirar deles suas próprias chances com o novo.

O segundo alerta que desejamos pontuar, nas práticas descritas anteriormente, consiste na responsabilização dos indivíduos através de um suposto "poder de escolha" dos estudantes sobre o seu futuro. Bauman (2001, p. 37), ao analisar a transição de um modo de organização social mais vinculado a certezas para o que ele nomeia como sociedade líquida, descreve duas características que alteraram a organização social e os modos como os indivíduos se relacionam com os outros e consigo mesmos, na virada do século XX para o século XXI. A primeira seria o declínio na crença de que existiria um fim (melhor) no caminho que percorremos, "um estado de perfeição a ser atingido amanhã, no próximo ano, ou no próximo milênio". A segunda mudança seria "a desregulamentação e a privatização das tarefas e deveres modernizantes" (BAUMAN, 2001, p. 37). Assim, tarefas que eram atribuídas aos Estados hoje são de responsabilidade dos indivíduos e de seus recursos.

Quase duas décadas depois da publicação da obra de Bauman, sob outra perspectiva, Butler (2017) diagnostica os modos pelos quais essa lógica de responsabilização dos indivíduos, através de processos de individualização, constitui-se como destino e não como escolha. Bauman (2008, p. 64), na obra Sociedade individualizada: vidas contadas e histórias vividas, já sinalizava a tônica que a individualização assume na sociedade atual, ao apontar que na "terra da liberdade individual de escolha, a opção de escapar à individualização e de se negar a participar do jogo individualizante não faz parte, de maneira alguma, da agenda. É intensificada nos contornos de uma racionalidade neoliberal". Para a pensadora social, a racionalidade neoliberal tem imposto a autonomia como ideal moral, ao mesmo tempo que destrói essa possibilidade, especialmente no campo econômico, "porque converte toda a população em seres potencialmente ou realmente precários" (BUTLER, 2017, p. 21).

Acreditamos que essas práticas individualizantes, ao responsabilizarem os estudantes por seus sucessos e seus fracassos nos percursos formativos, independentemente da etapa da escolarização que estiverem cursando, deixa de considerar que o ponto de partida de cada 
estudante é diferente. Ao promover oportunidades iguais na educação, tendo como foco o desenvolvimento de talentos dos estudantes e o aumento geral de desempenhos individuais, a escola não questiona as desigualdades sociais e econômicas produzidas nos contextos em que esses estudantes estão inseridos. Nessa esteira, os processos de individualização dos percursos formativos produzem uma naturalização das desigualdades, ao responsabilizar os alunos tanto pela construção do seu percurso formativo como pelo resultado final desse processo. Nessa chave, entendemos que o método coaching, ao operar pelas práticas descritas até aqui, segue alimentando uma lógica que transforma desigualdade social em desigualdade educacional (MASSCHELEIN; SIMONS, 2014b).

Como professoras, parece-nos necessário olhar com suspeita para as práticas oriundas de diferentes campos do saber, que buscam potencializar o trabalho docente através de estratégias do campo empresarial e do campo psicológico. Assim, encaminhamo-nos para a conclusão deste artigo defendendo o lugar da escola como espaço de produção e transmissão de conhecimento e de socialização, em um espaço público. E o lugar do professor como aquele que possui expertise em uma área de conhecimento e como adulto de referência das relações pedagógicas (SEFFNER, 2016).

\title{
4 PARA FINALIZAR: EM DEFESA DA DOCÊNCIA
}

\begin{abstract}
"Os professores que me salvaram - e que fizeram de mim um professor - não eram formados para isso. Eles não se preocuparam com as origens da minha enfermidade escolar. Eles não perderam tempo em buscar as causas nem em passar sermões. Eles eram adultos confrontados com adolescentes em perigo. Eles se disseram que havia urgência. Eles mergulharam. Perderam-me. Mergulharam de novo, dia após dia, mais e mais... Acabaram me tirando de lá. E muitos outros, comigo. Eles literalmente nos resgataram. Nós Ihes devemos a vida" (PENNAC, 2008, p. 33).
\end{abstract}

Em publicação recente, o professor Fernando Seffner nos convida a pensar a escola e os professores a partir de uma dupla chave. A escola, de acordo com o autor, precisa ser compreendida tanto como um espaço que se ocupa da alfabetização científica, através da transmissão de conhecimentos, como "um importante local de sociabilidade, a sociabilidade do espaço público e dos ideais republicanos, que não é a mesma sociabilidade experimentada no seio da família" (SEFFNER, 2016, p. 50). Nessa chave, o professor passa a ser compreendido como um profissional que possui expertise em uma área do conhecimento e como adulto referência, nas relações pedagógicas que empreende. O professor que ocupa esse papel seria "aquele capaz de enxergar 
que a educação escolar traz impactos muito além da disciplina que ele leciona, e impactos que dizem respeito à vida dos alunos, em aspectos muito diversos" (SEFFNER, 2016, p. 54).

Entendemos que o pesquisador, ao defender a docência tanto pelo domínio dos saberes específicos da disciplina que leciona, como pelos saberes docentes frutos da experiência em sala de aula, marca uma posição política frente à docência bastante divergente dos estudos analisados nesse artigo, que posicionam o professor como um coach de seus alunos. Os professores que assumem o papel de adulto referência são os professores que, no romance de Daniel Pennac, salvaram-Ihe e fizeram dele professor. Na obra Diário de escola, Pennac (2008) conta um pouco da sua trajetória como "aluno lerdo" e descreve que os professores que lhe salvaram foram aqueles que não buscaram saber as origens de sua "enfermidade escolar", mas acreditaram e investiram em uma relação pedagógica com o aluno.

Neste texto, ao dar visibilidade aos significados que uma cultura coaching tem produzido para a docência, tentamos alertar para alguns perigos que tal concepção pode trazer para os processos pedagógicos e educativos. Entre esses perigos, destacamos o papel do professor como motivador dos interesses dos alunos e a responsabilização dos estudantes, tanto pela escolha dos seus processos formativos, como pelo resultado desse processo. Ao colocar foco no aluno, na produção de uma customização para as relações pedagógicas, a ênfase estabelecida pelo método coaching acirra os processos de competitividade, produzindo a alta performance como objetivo final para a trajetória escolar. Parece-nos necessário interrogar sobre os resultados de um percurso escolar centrado unicamente em si mesmo. Quais seriam as possibilidades de seguirmos convivendo uns com os outros, de produzirmos horizontes comuns, em uma sociedade de indivíduos que tiveram negadas as experiências de colaboração, no espaço social que por mais tempo habitaram ao longo da vida? Assumir a ênfase coaching na educação parece-nos, nessa lógica, colaborar intensivamente para a constituição de uma sociedade em que cada um só é capaz de olhar para si mesmo.

Em contrapartida, ao colocar foco sobre o professor, parece-nos possível, nessa grade de leitura, identificar uma docência que se constitui pelo olhar individualizante, dentro dos coletivos formados por cada turma. A produção de uma educação cuja ênfase assume um tom de customização dos processos formativos, pela atenção constante às necessidades e aos interesses de cada aluno, a partir da "identificação de singularidades dentro do coletivo" (MATTEU CORREIO; MATTEU CORREIO, 2016) coloca em xeque as possibilidades de um fim comum para o processo de escolarização. É possível delimitar um objetivo comum para a escolarização, se cada professor deve 
manter-se vigilante às singularidades e definir planos individuais de aprendizagem para cada aluno que compõe o coletivo da turma? Parece-nos que a ênfase coaching dificulta a constituição da escola como espaço coletivo e a manutenção de um fim comum para o processo de escolarização.

A conformação de uma educação cada vez mais personalizada, centrada nos interesses dos alunos, pode estar produzindo, como apontamos na introdução deste artigo, o fim da profissão professor ou o desaparecimento de uma compreensão de que a principal função do professor seria ensinar (BIESTA, 2016). Para o autor, a linguagem da aprendizagem vai de encontro à linguagem educativa, exatamente porque a educação assume como objetivo principal fazer com que os alunos "aprendam algo, com determinados propósitos e que aprendam de alguém" (BIESTA, 2016, p.122). Constitui-se, nessa chave, um fim coletivo, que não tem como foco os interesses individuais, mas a promoção de processos coletivos de aprendizagem. A linguagem da aprendizagem parece incapaz de contemplar tais dimensões, por destituir o foco nos conteúdos e nas práticas coletivas, e centrarse nos percursos individuais. De acordo com Biesta (2016, p. 122), a linguagem da aprendizagem, cuja tradução é explicitada pela ênfase coaching, pauta-se pelos termos "individualista e individualizante", especialmente porque parece esquecer ou omitir que sempre aprendemos "algo de alguém". As relações de colaboração e a aprendizagem coletiva parecem inviabilizadas pela linguagem da aprendizagem.

Finalizamos a escrita desse texto, posicionando-nos em defesa dos professores como responsáveis pelo ensino de um conjunto de conteúdos aos recém-chegados (ARENDT, 2005) e também como adultos de referência que podem levar os alunos a "mergulhar de novo, dia após dia, mais e mais" (PENNAC, 2008, p. 33), com o propósito de "fazer a matéria falar, transformar um objeto em uma coisa, que é uma parte do nosso mundo. Fazer com que os estudantes entrem em contato e sejam tocados, isso é comunicar e desvendar o mundo". (MASSCHELEIN; SIMONS, 2014b, p.166). Ao final desse percurso de escrita, defendemos a manutenção da docência pela ênfase no ensino e dos professores como responsáveis por comunicar e desvendar o mundo para os mais novos. Acreditamos que essa tarefa não possa se realizar através das práticas operadas pelo método coaching, mas, sim, pela defesa de que "os professores devem ensinar, deve-se lhes permitir ensinar, e mais ainda, devem ter coragem de ensinar" (BIESTA, 2016, p. 128).

\section{REFERÊNCIAS}

ARENDT, Hannah. Entre o passado e o futuro. São Paulo: Perspectiva, 2005. 
BAUMAN, Zygmunt. Modernidade líquida. Tradução José Gardel. Rio de Janeiro: Jorge Zahar, 2001.

BAUMAN, Zygmunt. A sociedade individualizada: vidas contadas e histórias vividas. Tradução de Plínio Dentzien. Rio de Janeiro: Jorge Zahar, 2008.

BIESTA, Gert. Devolver la enseñanza a la educación. Uma respuesta a la desaparición del maestro. Pedagogia y Saberes, Bogotá, 44, p. 119-129, 2016.

BIRCK, Fernanda Kleber. ZILIOTTO, Denise Macedo. Coaching na Educação? Pesquisa-ação com gestores escolares. In: Acta Scientiarum, Maringá, V. 39, n.2, p. 165-175, 2017.

BUTLER, Judith. Cuerpos aliados y lucha política: hacia uma teoria performativa de la asamblea. Ciudade Autónoma de Buenos Aires: Paidós, 2017.

CASTRO, Edgardo. Vocabulário de Foucault - um percurso pelos seus temas, conceitos e autores. Belo Horizonte: Autêntica Editora, 2009.

DARDOT, Pierre. LAVAL, Christian. A nova razão do mundo: ensaio sobre a sociedade neoliberal. São Paulo: Boitempo, 2016.

FISCHER, Rosa Maria Bueno. Trabalhar com Foucault: arqueologia de uma paixão. Belo Horizonte: Autêntica, 2012.

GADELHA, Sylvio. Biopolítica, governamentalidade e educação: introdução e conexões, a partir de Michel Foucault. Belo Horizonte: Autêntica, 2009.

HAN, Byung- Chul. Psicopolítica. Barcelona: Herder, 2014.

HARGREAVES, Andy. Os professores em tempos de mudança- o trabalho e a cultura dos professores na idade pós- moderna. Lisboa: McGraw, 1998.

HATTGE, Morgana Domênica. Performatividade e inclusão no movimento todos pela educação. Tese (Doutorado em Educação) - Universidade do Vale do Rio dos Sinos, Programa de PósGraduação em Educação, São Leopoldo, 2014.

ILLOUZ, Eva. Intimidades congeladas: las emociones del capitalismo. Buenos Aires: Katz, 2007.

MATTEU CORREIO, Ivelise Fonseca. MATTEU CORREIO, Douglas. Coaching na Educação: uma metodologia de alta performance. In: Compartilhe Docência. São Paulo: V. 1, N. 1, p. 43-54, 2016.

JORNAL VS, Sapucaia contará com escola referência em Ensino Médio a partir de 2016. Novo Hamburgo, 2015.2 Disponível em: http://www.jornalvs.com.br/ conteudo/2015/11/noticias/regiao/245059-sapucaia-contara-comescola-referencia-em-ensino-medio-a-partir-de-2016.html. Acesso em: 10 set., 2017.

MASSCHELEIN, Jan. SIMONS, Maarten. Em defesa da escola. Belo horizonte: Autêntica, 2014a.

MASSCHELEIN, Jan. SIMONS, Maarten. A pedagogia, a democracia, a escola. Belo horizonte: Autêntica, 2014b. 
NÓVOA, António. Professores: imagens do futuro presente. Lisboa: Educa, 2009.

PÁTIO. Revista Pedagógica. Educação personalizada e abrangente. Porto Alegre: Artmed, mai. 2016. Disponível em: https://loja.grupoa.com.br/revista-patio/artigo/12535/educacaopersonalizada-e-abrangente.aspx. Acesso em: 19 ago., 2017.

PENNAC, Daniel. Diário de escola. Tradução Leny Werneck. Rio de Janeiro: Rocco, 2008.

PENSIN, Daniela Pederiva. Agenciamento e docência na educação superior. Tese (Doutorado em Educação) - Programa de Pós-Graduação em Educação, Universidade do Vale do Rio dos Sinos, São Leopoldo, 2017.

SEFFNER, Fernando. Escola pública e professor como adulto referência: indispensáveis em qualquer projeto de nação. In: Educação Unisinos. São Leopoldo: V. 20, n.1, 2016. P.48 -57.

SENNETT, Richard. A corrosão do caráter: as consequências pessoais do trabalho no novo capitalismo. Rio de Janeiro: Record, 1999.

SILVA, Paulo Carlos. Coaching na aula de Sociologia. Em Tese. Santa Catarina, v. 13, n.2 2016.

SILVA, Roberto Rafael Dias da. Políticas Contemporâneas de Constituição do Conhecimento Escolar: entre a perícia e a meritocracia. In: SILVA, Rodrigo M. D. da; SILVA, Roberto R. D. da; BERINCÁ, Dirceu. Educação, Cultura e Reconhecimento: desafios às Políticas Contemporâneas. São Paulo: Salta, 2015a.

SILVA, Roberto Rafael Dias da. Sennett e a Educação. Belo Horizonte: Autêntica, 2015b.

TARDIF, Maurice. LESSARD, Calude. $\mathbf{O}$ trabalho docente: Elementos para uma teoria da docência como profissão de interações humanas. Tradução João Batista Kreuch. Rio de Janeiro: Vozes, 2014.

VEIGA-NETO, Alfredo. Grupo de Estudos e Pesquisas em Currículo e Pós-Modernidade/ GEPCPós: concepções sobre a prática. In: REUNIÃO ANUAL DA ASSOCIAÇÃO NACIONAL DE PÓS-GRADUAÇÃO E PESQUISA EM EDUCAÇÃO (ANPED), 31., Caxambu, 2008. Anais [...] Rio de Janeiro: ANPEd, 2008.

\section{SOBRE AS AUTORAS}

\section{Renata Porcher Scherer}

Doutora em Educação, Universidade do Vale do Rio dos Sinos (UNISINOS); Instituto Federal de Educação, Ciência e Tecnologia Sul-rio-grandense- Brasil; Programa de Pós-Graduação em Educação Profissional e Tecnológica (ProfEPT); Grupo Interinstitucional de Pesquisa em Docências, Pedagogias e Diferenças (GIPEDIqCNPq).

E-mail: renatapscherer@gmail.com

ORCID: https://orcid.org/0000-0003-2331-1453

\section{Patrícia Gräff}

Doutora em Educação, Universidade do Vale do Rio dos Sinos (UNISINOS); Universidade Federal da Fronteira Sul- Brasil; Programa de Pós-Graduação em Educação; Grupo de Pesquisa em Políticas e Práticas de Inclusão (GPPPIn/UFFS/CNPq).

E-mail: patigraff@yahoo.com.br

ORCID: https://orcid.org/0000-0002-3315-2401 
Recebido em: 05/06/2020

Aprovado em: 02/12/2020

Publicado em: $13 / 12 / 2020$ 